\section{¿DERECHO DE FUGA? DERECHO DE MIGRACIÓN Y NACIONALIDAD COSMOPOLITA}

\author{
Víctor Granado Almena \\ Universidad Complutense de Madrid \\ vgranado@filos.ucm.es
}

\begin{abstract}
Transnational migrations are a useful hermeneutic so as to consider the political from of the world from the imbalances they generate. The increasing presence of people outside States poses chaIlenges with regard to: the reality of Human Rights, the power of the national States to control it and the degree of accuracy of the classic categories of political philosophy in order to understand globalization. Both global displacement and the increasing portion of people who are out of place question the old framework which linked territoriality, sovereignty and citizenship. In order to understand that reality, we shall therein after compare the thesis of both Mezzadra and Vitale on the experience of displacement. This aims at comprehending displacement as escape or as an exercise of Human Rights on free movement in global age.
\end{abstract}

KEY WORDS: Escape; ius migrandi; membership; cosmopolitanism; citizenship; border.

\section{INTRODUCCIÓN}

"Desde el punto de vista filosófico, las migraciones transnacionales destacan el dilema constitutivo en el corazón de las democracias liberales: entre las afirmaciones de la autodeterminación soberana por un lado y la adhesión a los principios universales de los derechos humanos por otro". Estas palabras (Benhabib, 2005, 14) enmarcan doblemente la reflexión que sobre el derecho de migración quiero desarrollar aquí. Por una parte justifican la elección del estudio de las migraciones como una clave hermenéutica adecuada para re-pensar la forma del mundo y la tradición de la filosofía política. Por otra parte señalan la tensión entre la territorialidad y la universalidad que marca el desarrollo de la globalización.

El exilio y la migración han ocupado un lugar propio en la tradición filosófica desde la antigüedad y en la actualidad la globalización ha hecho de ellos la piedra de

\section{THE RIGHT TO ESCAPE? RIGHT OF MIGRATION AND COSMOPOLITAN NATIONALITY}

RESUMEN: Las migraciones transnacionales sirven como clave hermenéutica para reflexionar sobre la forma política del mundo a partir de los desajustes que generan. La presencia cada vez mayor de personas fuera de sus Estados de procedencia pone a prueba: a) la realidad de los derechos humanos, b) el poder de control de los Estados nacionales y c) la vigencia de las categorías clásicas de la filosofía politica para comprender la globalización. El desplazamiento global y el aumento de personas fuera de lugar desafían la estructura que ligaba territorialidad, soberanía y ciudadanía. Para comprender esta realidad enfrentamos aquí las tesis de Mezzadra y Vitale respecto de la experiencia del desplazamiento. Esto significa comprender el desplazamiento bien como fuga o bien como un movimiento de salida y el desplazamiento como ejercicio del derecho humano al libre tránsito de las personas en la era global.

PALABRAS CLAVE: Fuga; ius migrandi; membresía; ciudadanía; cosmopolitismo; frontera.

toque con la que medir la vigencia de la forma política del mundo y las consecuencias que esa forma tiene sobre las vidas concretas de los seres humanos. La experiencia de un mundo en desplazamiento y las paradojas que ese desplazamiento genera nos permite plantear una revisión de conceptos como soberanía, territorialidad, ciudadanía y derechos humanos a partir de la reflexión sobre el derecho a migrar o ius migrandi.

La reflexión en torno al derecho a migrar en la actualidad refleja la doble consideración que respecto de la migración y el exilio se ha adoptado desde la antigüedad: por una parte, el desplazamiento (exilio y migración) vivido como una pérdida por quien debe abandonar su lugar de origen; por otra, esta misma circunstancia representa para otros la posibilidad de un nuevo comienzo, los cuales viven esta experiencia no como pérdida del hogar sino como su apertura al mundo. Se oponen de esta forma dos modos de interpretar la vida: desde la instalación estable en un lugar 
concreto en el mundo, o desde el desplazamiento. Pero esa distinción tan aparentemente clara es más borrosa de lo que pudiera parecer si entendemos que aquellas personas que dejan su lugar de origen y se desplazan a otros lugares pueden no estar permanentemente en desplazamiento y pueden desear instalarse y hacer propio el nuevo lugar al que llegan'. De este modo esa salida al mundo puede muy bien ser el abandono del lugar en busca del mundo, pero también puede ser la salida a un mundo en el que encontrar otro lugar. De manera que asumir completamente esa doble dimensión del desplazamiento -pérdida y universalidad-supone enfocar de un modo doble, a su vez, la reflexión sobre el derecho a migrar. Por ello la reflexión sobre la libre circulación de las personas debe reunir:

(a) el derecho a pertenecer a una comunidad política; y

(b) el derecho a poder salir de ella sin caer en el desamparo.

Es decir, esa reflexión ha de ser capaz de asistir tanto a quienes quieren abandonar su comunidad política de origen y aspiran a ser reconocidos como personas jurídicas allá a donde vayan, así como a las personas que luchan contra procesos de desnaturalización, desnacionalización o expatriación. Se trata, por tanto, de una reflexión que tiene en el derecho a ser miembro de una comunidad política y en el derecho a desplazarse las dos caras de una misma moneda.

En este sentido vinculo aquí la reflexión de Sandro Mezzadra (2005) sobre el derecho de "fuga" y de Ermano Vitale (2006) sobre la idea de una nacionalidad cosmopolita. Es preciso elaborar una reflexión sobre la estructura jurídico-política del mundo en que vivimos a partir de las experiencias del desplazamiento por ser éste el fenómeno que pone de manifiesto, con mayor claridad, las tensiones transnacionales a las que la forma nacional de la política y el derecho se ven sometidas por la globalización. Tensiones éstas que, de un modo u otro ${ }^{2}$, marcan la experiencia de todos los seres humanos en nuestros días.

Las propuestas de Mezzadra y Vitale nos presentan dos de los muchos movimientos que configuran el desplazamiento:

(1) desde dentro hacia afuera, es decir, como movimiento de sustracción o salida hacia el exterior;
(2) desde fuera hacia adentro, como deseo de pertenencia, es decir, por ser miembro de cualquier comunidad política.

Estas direcciones, aparentemente opuestas, sólo pueden distinguirse analíticamente en el desplazamiento ${ }^{3}$ y ambas deben estar presentes en una reflexión sobre el derecho a migrar. A partir de la relación de ambas dimensiones cabe preguntarse si puede configurarse el derecho a migrar como un derecho humano, si es posible concebirlo como un derecho de fuga, desde qué perspectiva tiene sentido plantearlo así, cuáles son las consecuencias de esto, o si debe ponerse el acento en el derecho de los seres humanos a ser admitidos como sujetos de derecho en cualquier comunidad política.

Por eso se construye aquí una mirada doble -hacia adentro y hacia afuera- en la que el espacio, el desplazamiento y la forma política del mundo revelan sus límites y costuras hasta dibujar un pequeño mapa de nuestra experiencia actual.

\section{Paradojas de la globalización: ASIMETRÍAS DEL DESPLAZAMIENTO}

El desarrollo y la expansión de la globalización someten a múltiples tensiones los límites nacionales de la forma jurídico-política de nuestro mundo, pero sobre todo invade y transforma las vidas concretas de las personas de modo desigual. El funcionamiento global de un mundo territorializado a partir de Estados nacionales provoca o aumenta desequilibrios entre distintas regiones de ese mundo, al tiempo que funda paradojas y perplejidades.

El dispar reparto de la población entre las distintas partes del mundo, el injusto reparto de la riqueza y la desigual atribución de derechos y, por lo tanto, la desigualdad entre los tipos de vidas posibles en este mundo global, actúan como factores de dinamización del desplazamiento y como factores de producción de paradojas en el mundo.

Si repasamos la evolución de los flujos migratorios, en los últimos años podemos ver con facilidad cómo las migraciones transnacionales han hecho crecer rápidamente el número de personas "desplazadas" así como su presencia 
global. Si en 1965 según datos de ACNUR podían encontrarse 77 millones de migrantes, en 1995 su número ascendía hasta los 120 millones. Actualmente su número se sitúa en unos 200 millones de personas ${ }^{4}$. Tal y como señala Sami Naïr (2006), aún a riesgo de caer en lo que Mezzadra llama una explicación supra-estructural de las migraciones, es preciso relacionar este rápido y significativo aumento de los migrantes con los desequilibrios entre las distintas regiones del globo $y$, sobre todo, con el desequilibrio que suponen de manera conjunta el crecimiento de la población mundial y el reparto de la riqueza. Durante los últimos decenios se ha producido un incremento demográfico sin precedentes y asimétrico en las distintas regiones del mundo hasta transformar las relaciones internacionales. Éstas han dejado de ser relaciones entre los distintos Estados para ser relaciones entre las distintas partes del mundo entre sí según las necesidades y recursos de cada una de ellas y su peso demográfico. Veamos esto con algún detalle. A comienzos del siglo XX la población mundial alcanzaba los 1.500 millones de personas, en los años 60 había crecido hasta alcanzar los 2000 millones y en el año 2005 superó los 6500 millones. Esto da cuenta del rápido crecimiento acaecido en los últimos 45 años y de cómo el desplazamiento encuentra en este enorme crecimiento y su reparto una de las causas principales del cambio de paradigma aquí presentado. Si en 1900 EE.UU. y Europa suponían el 30\% de la población mundial, en el año 2000 sólo representaban ya el 17\% y se espera que en el año 2050. se sitúen por debajo del 10\%. Esto significa que los paises pobres van a contribuir al crecimiento de la población mundial en un $98 \%$ en una situación que haría que en Europa en el año 2050, caso de no contar con población de otras regiones, sólo quedarían 2 personas activas por cada persona inactiva cuando en la actualidad la proporción es de 5 a 1 .

A tenor de los datos así presentados podemos concebir al menos la existencia de tres situaciones paradójicas en la relación entre un mundo global y la persistencia de una estructura territorial nacional.

En primer lugar podemos identificar la paradoja demográfica: por los datos facilitados por informes de la ONU podemos ver con claridad cómo el nuevo peso demográfico de las regiones más pobres y la necesidad de los paises ricos de "importar trabajadores" colaboran en el intento de mantener el statu quo en el marco de los procesos de glo- balización económica, de modo que junto con una política de cierre de fronteras para impedir el acceso de "las masas de población extranjera" se utiliza la inmigración tanto en EE.UU. como en Europa como una variable de ajuste estructural de la competencia de los mercados laborales. Las zonas más pobres del planeta son las más pobladas, y las más ricas, en el intento de mantener esa desigualdad, favorecen el desplazamiento selectivo de la población mejor preparada "excedente" de las regiones pobres, al tiempo que contienen o refrenan los procesos de redistribución o desplazamiento globales. Se emplea la variable global del desigual reparto de la población y la riqueza para ajustar en el ámbito nacional el mantenimiento de la desigualdad. Conviven de este modo por una parte el impulso del desplazamiento como forma estructural de producción de riqueza y por otra parte el cierre de fronteras y el control nacional del territorio y la población de los Estados. Esta paradoja demográfica pone de manifiesto la afirmación simultánea de dos procesos que se niegan mutuamente, a saber: (1) el proceso de producción económica global y (2) el intento de control nacional del territorio y de la comunidad política nacional.

La paradoja aduanera: el control nacional del incentivado desplazamiento transnacional se traduce en la desigualdad entre la libre circulación de mercancías y capitales y la circulación selectiva, condicionada y obstaculizada de personas. Mientras que por mor de la globalización se suprimen cada vez en mayor medida aquellas fronteras y aranceles nacionales que gravan la libre circulación de las mercancías y del capital, las personas constatan la inferioridad jurídica de su situación en comparación con las garantías jurídicas que disfrutan las mercancías y capitales. $\mathrm{Si}$ bien es cierto que mercancías y personas no emplean los mismos medios para su desplazamiento, ni éste conlleva el mismo tipo de consecuencias, si valdría esgrimir precisamente esta desigual condición entre mercancías y personas para denunciar una situación jurídico-política que "trata mejor" a las mercancías que a las personas, o mejor dicho que trata a ciertas personas como mercancías devaluadas.

La paradoja del desplazamiento dual: esas ciertas personas son las que centran en este caso la reflexión sobre el derecho a migrar. No porque el derecho a migrar sea una disposición que solo atañe a un cierto grupo de personas, sino porque en su formulación asume por completo 
la consideración del derecho como la ley del más débil (Ferrajoli, 1999). Tal y como afirma Balibar (2005, 83), la perplejidad que reclama nuestra atención es aquella que distingue modos distintos de aplicar la circulación o el desplazamiento de personas en función de sus circunstancias socio-económicas, procedencia y formación. Más que la desigualdad entre la libre circulación de capitales y mercancías y la negación del derecho a la libre circulación de la personas, lo que exige un análisis más detallado es la restricción del desplazamiento de las personas en función de su condición social y económica. Esta realidad dual configura una doble red de personas en desplazamiento y amplifica el carácter polisémico y heterogéneo de la frontera. Al tiempo que se refuerzan los controles fronterizos que intentan contener el desplazamiento de la población por motivos económicos, se potencia el libre movimiento de otra parte de la población a través del turismo. De ese modo podemos comparar la distinción espacial entre los desplazamientos restringidos o favorecidos en función de la procedencia cultural, la formación y el poder adquisitivos de las personas involucradas. De este modo podemos comparar en datos, y visualmente, esa dualidad del desplazamiento en los siguientes gráficos.

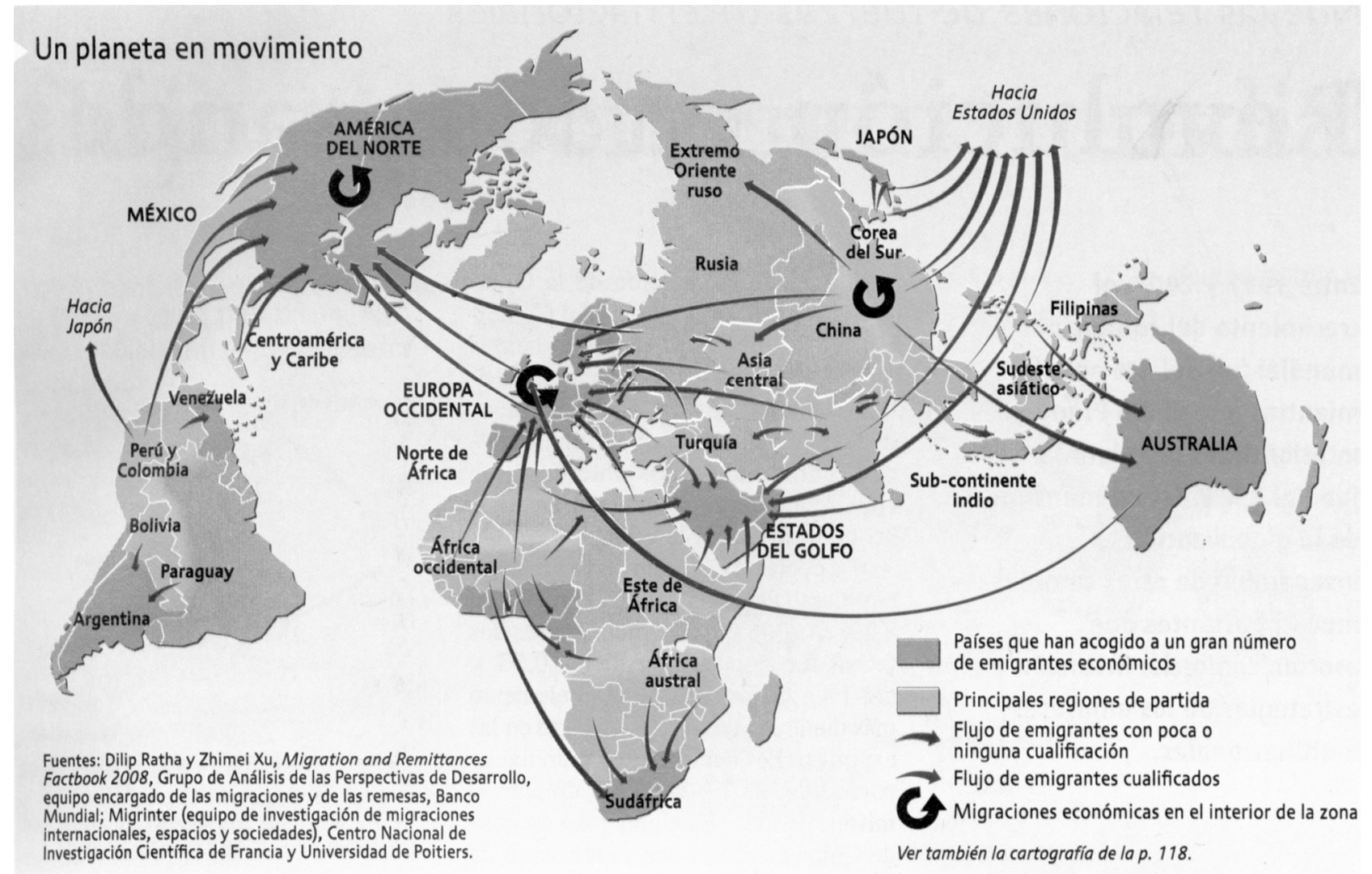

Si en el primero de los mapas podemos ver la procedencia y evolución del desplazamiento en el mundo, sumando dentro de este fenómeno flujos migratorios originados por motivos ecológicos, económicos y humanitarios, en el siguiente mapa podemos ver cuál es la nacionalidad de los turistas en el mundo. 


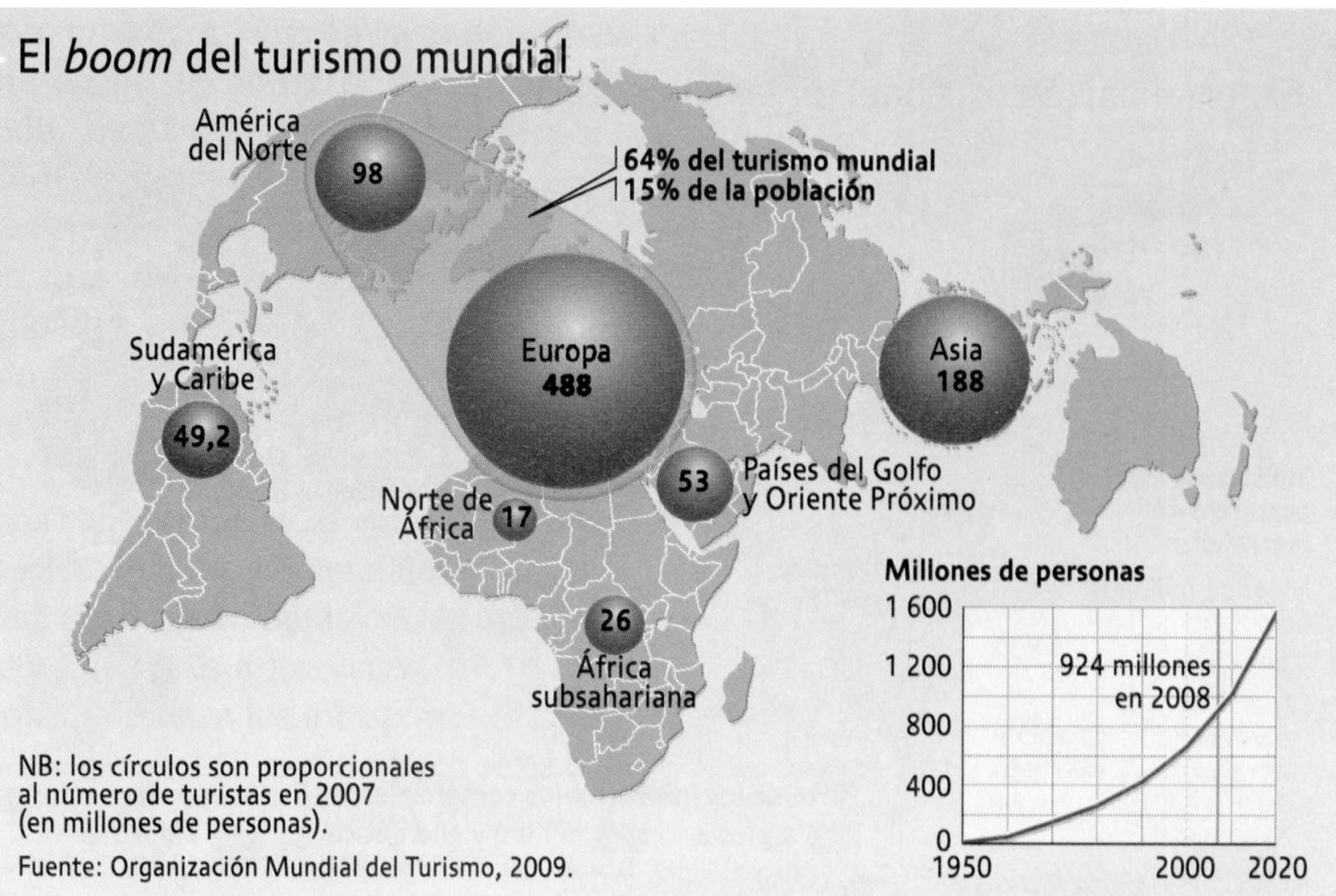

Mientras que en el primer gráfico se observa un desplazamiento estructural y generalizado en función del status económico y de la formación de la población en un desplazamiento fundamentalmente por motivos económicos, en el segundo caso vemos un desplazamiento libre, ocioso que deja ver cómo un 15\% de la población mundial representa el 64\% de los turistas del planeta. Esta situación puede interpretarse a la luz de la paradoja dual aquí señalada: mientras una parte de la población es desplazada y deja su hogar para desplazarse simplemente como mano de obra, otra parte de la población por su especial situación tiene la posibilidad de tener un lugar, un hogar y a su vez disfrutar de la salida puntual y lúdica al cosmos en una experiencia libre y fomentada por los distintos gobiernos.

Estos desarrollos del nuevo capitalismo y de la globalización han hecho inverosimil el ideal sedentario para poner en pie una estructura global que traspasa a todas las capas de la sociedad y que se encarna en la noción de "desplaza-

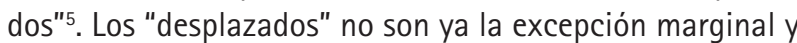
residual sino, recordando las palabras de Arendt sobre los refugiados, el emblema del nuevo mundo y un avance de nuestro futuro. Si hubo un tiempo en el que la homogeneidad y la estabilidad eran las fuentes de la personalidad de los seres humanos, ese tiempo ha pasado. Con los flujos migratorios iniciados en la Gran Guerra y los procesos de descolonización se generaron grandes bolsas crecientes de población "desplazada". Este hecho, sumado a los cambios ocasionados por la globalización, hace que la pluralidad, la movilidad y las identidades hibridadas sean cada vez más la norma y no la excepción.

De modo general, la situación de las "personas desplazadas" puede definirse como estar "fuera de lugar", al menos del lugar que jurídica, política y culturalmente se les presupone según el orden del mundo. Estas personas, 
en tanto que elementos desordenados y en tránsito, suponen un desafío para los Estados nacionales que deben enfrentarse a un fenómeno de movilidad y desplazamiento global con las instituciones y recursos heredados de los Estados-nación del siglo pasado. Será preciso juzgar sobre todo la adecuación entre el fenómeno y las herramientas con las que intenta "ser gestionado"6. Para ello podemos revisar ahora dos intentos teóricos de abordar esta cuestión: el que presenta Sandro Mezzadra con su tesis sobre el "derecho de fuga" y el de Ermanno Vitale con la reivindicación de una concreción normativa de un derecho que garantice y ampare a las personas desplazadas.

\section{Derecho de fuga}

En su obra Derecho de fuga: migraciones, ciudadanía y globalización (2005), Mezzadra reivindica la fecundidad de la sugerente y polémica categoría de fuga para reflexionar sobre la poliédrica realidad de las personas desplazadas. Tras señalar la vinculación tradicional de dicha categoría con la deserción del guerrero o con el éxodo bíblico, Mezzadra propone considerar el término en un sentido menos pretencioso y más general para así reconstruirlo (desde la experiencia histórica de los campesinos prusianos en el siglo XIX y la interpretación que de ella hizo Max Weber) y redefinirlo con el fin de convertirlo en una herramienta útil para la comprensión actual de los movimientos migratorios y sus consecuencias.

Con la categoría de fuga, Mezzadra pretende sobre todo remarcar la dimensión subjetiva de los procesos migratorios, es decir, aquella dimensión que haciendo resaltar su naturaleza específica de movimiento social, impide su reducción a procesos casi naturales, automáticamente determinados por causas objetivas de naturaleza económica o demográfica: "La defección anónima de los migrantes", como observa Mezzadra $(2005,45)$, "se coloca en línea de continuidad con los comportamientos de sustracción al despotismo, al sistema de plantación y al sistema de fábrica, que constituyen el lado subjetivo de la movilidad del trabajo a lo largo del arco de la historia del modo de producción capitalista". Vinculada a la experiencia migratoria, la categoría de "derecho de fuga" viene a cumplir de este modo una doble función:
(1) Ir en contra de la reducción del migrante a "típico exponente de una cultura", de una etnia, de una comunidad, al poner en evidencia la singularidad de los migrantes.

(2) Derivada de esa insistencia en la singularidad de los migrantes, el concepto de fuga permite iluminar los aspectos ejemplares de su condición y de su experiencia, definida en el punto de intersección entre una potente tensión subjetiva de libertad y la acción de barreras y "cofines" a las que corresponden técnicas de poder específicas. De este modo, pone en cuestión la noción moderna de la libertad de movimiento.

Según afirma Mezzadra, al poner el énfasis en la subjetividad de los migrantes se subrayan los elementos de riqueza de los que son portadores los migrantes eludiendo la imagen del sujeto débil marcado por el castigo del hambre y la miseria, una imagen que se presta, sin duda, a lógicas paternalistas que relegan a los migrantes a una posición subalterna, negándoles la posibilidad de subjetivación. A pesar de ello, Mezzadra sostiene que resaltar la subjetividad de los migrantes no equivale a borrar las causas objetivas del origen de la migración ni tampoco significa olvidar el modo en que su condición está profundamente caracterizada por circunstancias de privación material y simbólica, por procesos de dominación y explotación, además de por dinámicas específicas de exclusión y de estigmatización.

En esta misma línea, para Mezzadra este énfasis en la individualidad subjetiva de los migrantes permite aplicar las reflexiones actuales sobre la ciudadanía al análisis de las migraciones transnacionales. Mezzadra asume una noción marshalliana de ciudadanía, si bien remarca la proliferación de espacios diaspóricos y la descomposición de la pertenencia, procesos ambos favorecidos por las actuales migraciones transnacionales. Podemos conectar la reflexión sobre estos procesos de fragmentación de la pertenencia con el papel que el fenómeno migratorio tiene en ellos. A juicio de Mezzadra es preciso resaltar el carácter subversivo de los migrantes. Desde este flanco de análisis, la presencia de seres humanos en situación de ilegalidad subvierte y desafía los intentos de los Estados nacionales de mantener el control territorial y de salvaguardar la noción de soberanía. La mera presencia de estas personas, que se encuentran más allá de la ciudadanía, habitando 
en los márgenes de la comunidad política y en el núcleo de la actividad económica de la sociedad, cuestiona la construcción institucional de los Estados nacionales. La existencia ilegal de los migrantes reaviva en nosotros el recuerdo del carácter excluyente de la institución de la ciudadanía, en tanto que límite que discrimina el acceso a la comunidad.

En esta reinterpretación del migrante como sujeto político subversivo se encuadra la propia noción de la fuga. La fuga, en tanto que sustracción al poder despótico, escenifica el movimiento subjetivo del migrante de vaciar de contenido el poder al que se enfrenta mediante su huida y repercute sobre la estructura política del mundo por desatar con su sola presencia la crisis en las categorías centrales del pensamiento y las instituciones políticas modernas.

\section{Fuga VERSUS NACIONALIDAD COSMOPOLITA}

La fuga, la huida del mundo, parte de la idea romántica de la posibilidad de una sustracción del mundo. Nombra "el intento de dejar el mundo atrás". Esta huida sólo es posible si existe un afuera del mundo al que poder huir para de ese modo salir del mundo en el que nos encontramos, dejándolo atrás. La experiencia de nuestro tiempo parece mostrarnos que esa huida no es ni fáctica ni lógicamente posible en nuestros días cuando no existen ya varios mundos genéricamente distintos dentro de éste 7 . De manera que esa huida, esa búsqueda del afuera del mundo, no es una posibilidad emancipadora y libertaria, sino que en tanto que la huida conlleva una deserción del mundo supone abrazar la ilegalidad, la invisibilidad y la exclusión. Esta huida no es una salida a otro lugar sino la entrada en una existencia marginal que no es sino otra forma de estar en prisión: "en presidio está ahora, con una leve diferencia, que no está encerrado dentro sino fuera"s. Esta salida o huida de la fuga tiene en el pirata una de sus encarnaciones arquetípicas. La figura del pirata como máximo exponente del hombre libre, liberado de la ley y la sociedad, puede interpretarse a la vez como la de aquel proscrito y maldito, eternamente exiliado, condenado a vagar errante sin posibilidad de encontrar descanso en ningún lugar: la figura, en definitiva, de alguien encerrado fuera y no dentro, pero encerrado.
En cambio, me parece acertado afirmar con Mezzadra $(2005,94)$ que pensar políticamente sobre los procesos migratorios significa al mismo tiempo pensar sobre el conjunto de la crisis, de "los desplazamientos" y de las tensiones que marcan hoy el concepto y la propia práctica institucional de la ciudadanía desde una perspectiva específica.

A juicio de Mezzadra, en las últimas décadas parece haberse disuelto un orden determinado del mercado laboral y de la ciudadanía que se había reorganizado alrededor de un código fundamentalmente inclusivo. Un orden que, a partir del soporte que le proporcionaba el trabajo y el tiempo "planificado" a largo plazo, hacía posible el desarrollo de una trayectoria vital en la que realizar un ascenso social capaz de incluir en el cuerpo social y en la comunidad política a los sectores marginados de la población. Las nuevas formas del capitalismo flexible y el desarrollo de una sociedad post-fordista repercuten directamente sobre la capacidad inclusiva de las sociedades actuales respecto de los movimientos migratorios. El trabajo, y la movilidad social que éste posibilitaba, era el medio en el que las sociedades occidentales incorporaban social y políticamente a los migrantes. Más allá de los reparos ético-normativos que tenemos ante esta práctica, al perder el trabajo su centralidad en las sociedades actuales quedan en suspenso los mecanismos prácticos de incorporación de la población migrante. De esta forma no parece descabellado conectar la crisis de la idea de movilidad o ascenso social con la crisis de la noción de ciudadanía.

Mezzadra señala que se está registrando una extensión semántica de la noción de ciudadanía, que va más allá del simple criterio jurídico-formal. La ciudadanía se dispone efectivamente a transformarse en un concepto denso en significados, que involucra especialmente los criterios de adhesión subjetiva a un ordenamiento: identidad y participación, derechos y deberes de "geometría variable". Para Mezzadra se privilegia un punto de vista dual de la titularidad de los derechos y de su goce efectivo y, por ello, se revela así la ciudadanía como una noción de gran utilidad analítica desde al menos tres puntos de vista: (1) permite tratar la problemática de las instituciones y de la calidad de la vida pública; (2) abre la perspectiva de investigación particularmente interesante sobre la relación entre universalismo de los derechos y particularismo de la pertenencia; y (3) permite finalmente tematizar las tensiones que hoy se 
manifiestan, tanto en el plano internacional como en el interno, entre procesos globales e identidades locales. Desde este punto de vista, Mezzadra asume el planteamiento de Thomas Marshall (1998) según el cual toda la experiencia política moderna se interpreta desde la progresiva inclusión en la ciudadanía de sujetos originariamente excluidos de la misma y del continuo enriquecimiento intensivo de las determinaciones de los derechos de los ciudadanos, culminando a mediados del siglo XX con el reconocimiento de algunos derechos sociales fundamentales. Pero junto a esta intepretación, es preciso no perder de vista un significado más simple del concepto de ciudadanía es aquel que indica la posición de un sujeto frente a un Estado determinado en relación al cual se es o ciudadano o extranjero. Este es el sentido excluyente de la ciudadanía. Una dimensión exclusiva de la línea que separa un "adentro" y un "afuera". Este es un aspecto, el de la exclusión, que en ocasiones se deja de lado en los análisis filosóficos y sociológicos respecto de la ciudadanía. Tal y como señalaba A. Sayad en su texto La doble ausencia (2010), pensar en la inmigración significa pensar el Estado, y es el Estado el que se piensa a sí mismo pensando la inmigración. La definición de los códigos de inclusión dentro del espacio de la ciudadanía y la regulación de los mercados de exclusión son las grandes cuestiones que el Estado está obligado a pensar y repensar a causa de la presencia de extranjeros en su territorio. Confluyen aquí el universalismo de los derechos y el particularismo de la pertenencia que define la ciudadanía.

Una vez apuntadas estas coincidencias y presentada someramente la categoría de la fuga, paso en lo que sigue a comentar la tesis de Mezzadra polémicamente de la mano de la reflexión de E. Vitale. Para Vitale (2006) el derecho a la migración es un corolario del derecho a la libertad personal de circulación, pero el autor de lus migrandi juzga muy críticamente la tesis de Mezzadra sobre el "derecho de fuga". A juicio de Vitale, y ya desde las primeras connotaciones del término, la fuga, en tanto que procedimiento de huida que sitúa al huido en el terreno de la ilegalidad, no puede ser una categoría sobre la que construir un derecho. Vitale comparte con Mezzadra el énfasis en las condiciones y motivaciones subjetivas de los migrantes y, precisamente por ello, critica duramente la interpretación supra-estructural de los migrantes que hace Mezzadra al asimilarlos a revolucionarios que pretenden, en un movimiento vital plenamente consciente de sus consecuencias e impulsado por ellas, migrar para poner en crisis el sistema político vigente. La tendencia a la creación de espacios diaspóricos, que señala Mezzadra, representa para éste un ejemplo de la disolución progresiva de la nacionalidad a la luz de una concepción marshalliana de la ciudadanía destinada a supeditar también los derechos del individuo a los del ciudadano. Esta noción se ve superada y rechazada de forma radical por las teorías de los derechos fundamentales porque vincula la titularidad de los mismos al status de ciudadano. Pero el "derecho de fuga" a ojos de Vitale $(2006,222)$, más que un derecho, aparece como una actitud que pone la mira en las consecuencias, en las estructuras mundiales de poder, y no un derecho subjetivo capaz de convertirse en un derecho positivo sujeto a la garantía de un ordenamiento jurídico nacional o supranacional. Se trataría, en todo caso, de un derecho natural o moral que excede el ámbito del derecho positivo, una actitud moral asumible -la de la fuga- ante situaciones que ponen en peligro la integridad física y la propia vida.

En cambio, a su juicio, sí puede convertirse en derecho positivo el derecho a la migración, del mismo modo como lo son el derecho a la integridad física o el derecho a la libertad personal. Resistencia y fuga son dos soluciones ante la opresión, pero ninguna de ellas puede, según el razonamiento de Vitale (siguiendo así la estela de Kant), positivizarse e integrarse en un ordenamiento jurídico de forma consistente en razón de su naturaleza moral extrajurídica. La fuga no sería un derecho positivo, sino la pretensión moral de sustraerse a un derecho positivo que se considera claramente injusto y como tal tiene como objetivo declarado escapar de unas condiciones de vida que se resuelven intolerables. Cualquier otra derivada de esta huida, si se quieren interpretar así las motivaciones subjetivas de los migrantes, comparece siempre a la espalda de ese acto y no es su finalidad. Una suerte de derecho natural a la conservación de la propia vida que en nada está vinculado al deber al prójimo y que no tiene como objetivo un cambio estructural en el paisaje político del mundo, sino una mejora individual de las condiciones de vida.

El hecho de considerar a los migrantes como "fugitivos" tiene tan sólo consecuencias negativas para comprender el fenómeno y para las vidas de las personas concretas, al dificultar el reconocimiento del derecho de membresía 
de los migrantes, es decir, de su estatuto de personalidad jurídica al margen de la condición de ciudadano o nacional de un Estado. Un sujeto de derecho y no un objeto de asistencia.

\section{IUS MIGRANDI}

En la reflexión de Vitale (2006) encontramos una potente llamada a desarrollar una nueva forma política del mundo capaz de generar un derecho positivo de migración. Sus tesis chocan en cierto punto con la posición de Benhabib (2005) y su reivindicación del derecho de membresía, aunque intentar conciliar ambas posturas a partir del siguiente desarrollo y engarce de ambas visiones y propuestas:

(1) Es preciso señalar que en la actualidad los derechos humanos están supeditados a la condición de ciudadanía, tal y como lo expresa Arendt en su análisis de la relación entre los derechos del hombre y del ciudadano. Por ello sería necesario desligar ambas dimensiones y apostar por un desarrollo de los derechos humanos en un sistema jurídico internacional global en lugar de persistir en el mantenimiento en exclusiva de la lógica de la ciudadanía nacional. Ello exigiría de modo transitorio facilitar las condiciones de acceso a la ciudadanía nacional.

(2) La permeabilización del acceso a la comunidad política supone el abandono de la procedencia como fundamento de la comunidad. Sería ésta una situación intermedia en la que la consolidación del derecho de membresía sería el mecanismo que permitiría transformar un marco nacional de soberanía restrictiva en un modelo de "nacionalidad cosmopolita" que no tenga la territorialidad sino la condición humana como base.

\subsection{Sobre la "membresía política": del hombre y del ciudadano}

En este punto podemos considerar de la mano de Hannah Arendt y Seyla Benhabib la vigencia de la crisis de la relación entre derechos humanos y derechos del ciudadano a partir de las experiencias concretas de exiliados, refugiados y migrantes en general.
Nacionalidad y ciudadanía son dos conceptos ligados en el moderno sistema del Estado-Nación. Tanto por ampliación, por el proceso de globalización, cuanto por concreción, por los procesos locales de creación de grupos y comunidades de interés; por la acción de ambos movimientos de desterritorialización y de territorialización, la forma política e institucional del mundo sufre grandes tensiones sobre las que es preciso reflexionar.

En su reflexión sobre los derechos humanos, Arendt plantea la necesidad de considerar los derechos humanos una realidad inexistente al quedar subsumidos bajo la categoría de los derechos de ciudadanía, de modo que se establece un lazo entre "derecho-ciudadanía-nacionalidad". Esto nos permite afirmar con Arendt la idea según la cual "la emancipación moderna significó nuevas condiciones de exclusión" ${ }^{\prime \prime}$. La construcción de la comunidad Ileva implícito, en el establecimiento de un dominio y un límite de la misma, la exclusión de los otros de ese orden ciudadano. La pertenencia a la comunidad, la ciudadanía establecida a partir de la procedencia de los individuos lleva a construir un orden político sobre la base de la parcelación del mundo mediante comunidades territoriales en las que habitan las personas que proceden de ese lugar. Este diseño del mundo queda desmentido por todo movimiento de población, por todo desplazamiento que implique la existencia de personas foráneas a las puertas de otras comunidades políticas. Ser ciudadano supone ser propietario del mismo territorio y de la comunidad política que sobre él se yergue. Esa "procedencia-común-propiedad" de los ciudadanos les faculta para discriminar quien puede o no acceder a la "comunidad-territorio" y en qué condiciones. La procedencia, como clave de edificación de la comunidad política, dibuja un espacio excluyente, de fronteras pretendidamente aseguradas. Bajo este orden territorial, los derechos humanos no bastan por sí solos para garantizar el fin de la condición de paria de todos aquellos que se encuentran "fuera del lugar que les pertenece", es decir fuera de los muros de su comunidad. De este modo sólo cuando se cuenta con el amparo de un Estado, del cual se es ciudadano, cabe esperar que tales derechos puedan ser defendidos con cierta seguridad. Algo que podemos leer de este modo en palabras de Arendt $(2004,357)$ :

"Los derechos del hombre, después de todo, han sido definidos como inalienables porque se suponía que eran independientes de todos los gobiernos, pero resultó que en el

ARBOR Vol. 188755 mayo-junio [2012] 489-502 ISSN: 0210-1963 
momento en que los seres humanos carecian de su propio gobierno y tenían que recurrir a sus mínimos derechos, no quedaba ninguna autoridad para protegerles ni ninguna institución que deseara garantizarlos".

Esta situación escenifica una paradoja según la cual, mientras la figura del refugiado debía ser la que encarnase los derechos del hombre, era por el contrario la que cuestionaba su vigencia/existencia efectiva. De esta manera la figura del refugiado marca la crisis radical de este concepto (Arendt, 2004, 378). En el sistema de la Nación-Estado los Ilamados derechos sagrados e inalienables del hombre aparecen desprovistos de toda tutela y realidad en el preciso momento en el que no pueden ser consignados como derechos de un ciudadano de un Estado, en ese momento es cuando se revela en qué sentido tratamos con un concepto límite ${ }^{10}$.

Esta relación paradójica entre el trío formado por: la $\mathrm{Na}-$ ción-Estado/los derechos del hombre/los derechos del ciudadano queda ya puesta de manifiesto desde el origen de tales nociones en la modernidad. La Declaración de 1789 presenta la conjunción de ambas nociones en su título, de "Los derechos del hombre y del ciudadano". De este enunciado pueden deducirse dos posibles relaciones: (a) los dos términos nombran dos realidades autónomas; (b) ambos términos designan un sistema unitario en el cual los derechos del hombre quedan subsumidos, siempre contenidos y ocultos en los derechos del ciudadano. Como sugiere Arendt, "el hombre de los derechos" representa la primera y única aparición real del hombre sin la máscara del ciudadano que constantemente lo encubre. En la obra de Arendt no se encuentra el modo de superar positivamente esta distancia entre los derechos del hombre y los derechos del ciudadano. Benhabib, al reflexionar sobre esta situación y sobre las limitaciones de la reflexión arendtiana para encontrar una salida a esta situación, hace de la "membresía política" y, más concretamente, del "derecho a ser miembro de una comunidad política" la vía de salida de este laberinto.

Los procesos de expansión global del nuevo capitalismo y el desplazamiento que genera en su desarrollo hacen entrar en crisis la noción tradicional de soberanía en su modelo territorial-nacional. Esto hace preciso nuevas formas que permitan ir más allá de la procedencia, y articular modos de membresía política que amparen a todas aquellas "personas desplazadas", que encontrándose fuera de los límites del Estado del cual son nacionales ya no se vean desprovistos de su condición de sujetos jurídicos.

Según Benhabib (2005, 101 y ss.), el desarrollo del derecho internacional de migraciones y de los derechos humanos tras la aprobación de la Declaración Universal de 1948, con la prohibición de la desnaturalización arbitraria de los seres humanos (art. 15.2) ${ }^{11}$, apunta a la afirmación de un "derecho humano a ser miembro". Mediante este razonamiento, dicha autora hace de la prohibición de la desnaturalización y la afirmación del derecho de membresía, las dos caras de una misma moneda que señala, al margen de condiciones contingentes, la personalidad jurídica de los seres humanos más allá de su ubicación concreta en un Estado y de cualquier otra consideración.

Benhabib (2005) examina las fronteras de la comunidad política centrándose en la noción de "membresía política", que viene a significar los principios y prácticas para la incorporación de forasteros, extranjeros, inmigrantes, recién llegados, refugiados y asilados a entidades políticas previamente existentes. Las fronteras políticas definen a unos como miembros y a otros como extranjeros. La condición de miembro es significativa cuando va acompañada de rituales de ingreso, acceso, pertenencia y privilegio.

El sistema moderno de Estados nacionales ha regulado la pertenencia a la comunidad política en términos de ciudadanía nacional. Pero en la actualidad han surgido nuevas modalidades de membresía, de modo que según Benhabib esto tiene como resultado que las fronteras de la comunidad política, tal y como las define el sistema de Estados nacionales, ya no son adecuadas por sí solas para regular la condición de miembro. Junto con la invisibilidad de las fronteras del Estado, también han sido invisibles las prácticas institucionales que regulan la admisión y la pérdida de la condición de membresía política.

Al entrar en crisis la noción de ciudadanía nacional, como consecuencia de las tensiones que sufre la soberanía estatal en el proceso de globalización, emergen en el mundo contemporáneo espacios subnacionales y supranacionales para adhesiones y acciones democráticas, las cuales según señala Benhabib $(2005,14)$, deben promoverse en colaboración con los entes políticos ya existentes. En esto estribaría su tesis de las iteraciones democráticas (Benhabib 2005, 125 y ss.), según la cual la existencia de esas realidades locales 
y supranacionales pueden servir como apoyo de la ciudadanía nacional para ampliar la extensión y la intensión de este concepto. Ello se fundamenta en la crisis del modelo "westfaliano" de soberanía, la cual presupone una autoridad política dominante y unificada, cuya jurisdicción sobre un territorio claramente demarcado es suprema. Pero la globalización coloca las funciones administrativo-materiales del Estado en contextos crecientemente volátiles que exceden con mucho la capacidad de cualquier Estado de influir individualmente en decisiones y resultados. Se produce de este modo una crisis de la territorialidad que conlleva la crisis de la noción de soberanía y, de este modo, se reclaman nuevas formas de articulación política que en este nuevo marco amparen a quienes se encuentran en el margen o más allá de las formas de pertenencia clásicas. En este punto se tornan insuficientes y paradójicos los desarrollos actuales del Derecho Internacional de los derechos humanos al incorporar las contradicciones derivadas del choque entre el carácter transnacional de estos derechos y la soberanía nacional, de modo que privilegia ésta sobre aquéllos. De esta forma, el reconocimiento del derecho a una nacionalidad contemplado por los derechos humanos queda sin contenido al no obligar a los Estados nacionales a facilitar la nacionalidad a aquellas personas desplazadas o sin Estado que así lo soliciten. En el mismo sentido, el derecho de asilo cae en esta misma contradicción en tanto que podemos exponer el contenido de este derecho en "tener derecho a salir de un lugar sin tener derecho a entrar en otro, lo que significa estar condenado a quedar fuera de lugar o sin lugar".

La crisis de la noción "westfaliana" de soberanía y de la territorialidad hace que las naciones territorialmente delimitadas no sólo se vean cuestionadas en su derecho a controlar sus fronteras, sino también en sus prerrogativas de definir las "fronteras de la comunidad política".

\subsection{Derechos más allá de la nación}

La situación de los desplazados o personas en tránsito pone al descubierto:

a) las carencias redistributivas del proceso de globalización económica;

b) las insuficiencias del sistema jurídico para proteger los derechos de aquellas personas que se encuentran fuera del Estado del cual son nacionales; c) la incapacidad de las sociedades occidentales para dotar de una forma política al mundo acorde con la dimensión y alcance del desplazamiento que no tenga en la procedencia su punto central.

Por todo ello, es preciso apuntar un juicio sobre la posibilidad, conveniencia o inconveniencia de apostar por la construcción de un nacionalidad cosmopolita al amparo de la crisis de la ciudadanía que plantean nuestros autores, reflexionar sobre la necesidad de adecuar las estructuras administrativas a la realidad que nos rodea bajo un criterio que la oriente y ordene según se adopte la perspectiva del derecho de fuga como derecho humano o la reivindicación de derechos para las personas en tránsito que sufren la exclusión. Mientras que en un caso se trata de una reivindicación positiva del derecho a migrar como movimiento de salida de un orden injusto, en el otro caso se pone el acento en asegurar y mantener la protección de las personas desplazadas y de su derecho a pertenecer, en pie de igualdad, a una comunidad política. Mi intención es poder llegar a recomponer una posición unitaria al respecto, una vez recorrida la relación polémica y dialéctica que arrojan ambas miradas sobre la realidad del desplazamiento en un mundo global.

Un mundo de políticas crecientemente desterritorializadas precisa de nuevas formas de reconocimiento del status jurídico de los seres humanos que vayan más allá de la procedencia-territorialidad como clave interpretativa.

Estas formas de reconocimiento no consisten en una flexibilización de los criterios de admisión en la ciudadanía nacional, sino en una articulación distinta del sistema de derechos. Se trata de transformar los privilegios que la ciudadanía mantiene sólo para aquellas personas que forman parte de su dominio en derechos inherentes a los seres humanos al margen de su procedencia. Se trata de redibujar la forma política del mundo para disolver la exclusión inherente a la distinción entre el dentro y el fuera de la comunidad política que dibujan la territorialidad y la procedencia.

Por ello, pensar sobre el desfase de la forma política del mundo desemboca, a mi juicio, en una reflexión sobre la ciudadanía en un mundo globalizado. Una reflexión sobre los modos de hacer compatible la existencia de Estados nacionales en un mundo global con la defensa 
de la condición humana de todo individuo al margen de su procedencia alli donde se encuentre. Esto implica una profunda reconsideración del derecho de pertenencia a la comunidad política, una trasformación del propio concepto de ciudadanía para intentar responder a la realidad del mundo en nuestros días. Se trata de poner como base de esa demanda el "derecho a tener derechos" enunciado por Arendt, es decir, el derecho de toda persona a ser tratado como sujeto de derecho con independencia de otras consideraciones que desemboquen en una estructura política del mundo capaz de asumir la idea de una ciudadanía cosmopolita, desligada de la territorialidad y la soberanía, una ciudadanía no excluyente.

Mi posición parte, por tanto, de la afirmación de la condición humana como la categoría central de la que derivar esa noción de ciudadanía cosmopolita. Se toma esta afirmación como el punto de partida desde el que comenzar a reflexionar sin ir más allá de él. Es preciso reconocer la imposibilidad de una fundamentación para la noción del "derecho a tener derechos" y de los derechos humanos en general, y esta carencia impide remontarse más allá en la argumentación. Ahora bien, eso no impide afirmar que los derechos humanos son indispensables para defender a los seres humanos de la violencia, así como también es posible ampararse en la historia para esgrimir el respeto a la condición humana como piedra angular sobre la que pensar una nueva forma política más justa e integradora para el mundo ${ }^{12}$.

Parece acertada la idea según la cual caminamos hacia un modelo postnacional de pertenencia en el cual el estatuto de la humanidad -basado en el carácter universal de los derechos humanos reconocidos y garantizados por el desarrollo internacional de los derechos humanos- tendería a reemplazar a la ciudadanía como origen de los derechos. De manera que ese desarrollo internacional de los derechos humanos penetrase en el derecho positivo de los Estados democráticos para ampliar así el alcance de los derechos individuales, con una creciente incorporación de los extranjeros en los espacios políticos existentes, con la consiguiente y paulatina pérdida de importancia de la ciudadanía nacional (Soysal 1994).

Se trata, por tanto, de invertir la relación entre pertenencia y procedencia: si hasta ahora la procedencia del individuo regulaba su pertenencia o no, y en qué medida a la comu- nidad política, es decir, marcaba el rango de posibilidades de su vida en función del lugar en el cual se encontrase, se trataría de invertir la relación y hacer derivar el derecho a pertenecer a toda comunidad política del derecho previo de todo individuo a ser considerado siempre y en toda circunstancia como sujeto de derecho, lo que equivale a convertir la apelación a su condición humana en el dato último del que derivar sin exclusión su pertenencia a una comunidad política dada al margen de su procedencia. Este argumento descansa sobre el intento de eliminar la exclusión (o al menos reducirla a su mínima expresión) que presupone la distinción entre ciudadanos y no-ciudadanos (o, lo que es lo mismo, entre nosotros y los otros) en las concepciones tradicionales de la ciudadanía que de un modo $u$ otro incurren en la primacía de la procedencia sobre la pertenencia; o en la identificación de la pertenencia con la adhesión comunitarista a una cultura nacional concreta. Aquí por pertenencia entiendo, en cambio, el derecho a pertenecer a toda comunidad política, es decir, a ser tratado como un sujeto de derecho en todo lugar y circunstancia. Esta es, por tanto, una reflexión sobre el límite como concepto, en tanto que limes de la comunidad política, y por ello también una reflexión sobre la frontera y sobre como los limites políticos y geográficos, aunque transfigurados por los procesos de (des-/re-)territorialización desarrollados por la globalización, tienen efecto sobre las vidas de todos nosotros.

Del mismo modo, y derivado de la apuesta por ese derecho de pertenencia a la comunidad política, es preciso repensar cómo debemos entender el nuevo demos resultante de incluir en la comunidad a todos aquellos que la habitan con independencia de su procedencia, algo que equivale a reformular la pregunta ¿Quiénes somos nosotros? Pero la respuesta a esta pregunta no son los contenidos culturales de una clase cerrada y relativamente homogénea de individuos, sino quiénes y cuántos son los afectados por el alcance de nuestras acciones y, por lo tanto, tienen derecho a participar en la decisión. Por ello se trata de una pregunta por el quién, por el sujeto de la acción y no por el cómo de ese sujeto. Es la pregunta que traduce, al ámbito del espacio público y la democracia, la reconsideración de los límites de la comunidad política en el intento de no separar la forma y la materia de nuestro mundo y que persigue recortar en él la distancia entre el reconocimiento teórico de derechos y las injusticias y el desamparo sufridos por los individuos en la práctica. 
desde causas económicas a conflic-

1 La distinción se vuelve problemática si asumimos el desplazamiento como un estado, una situación vital sin esencializar ni a las personas que se desplazan ni al desplazamiento como fenómeno, y estamos abiertos a mirar y reevaluar el proceso y las experiencias que genera desde múltiples puntos de vista. Por ello, no hay desplazados sino personas en desplazamiento $y$, por ello, la comprensión de esta compleja realidad deberá asumir, al menos, una doble mirada del fenómeno.

2 Si bien en unos casos vivimos el desplazamiento de una manera sólo potencial, en otros, muchas personas ven realmente marcadas sus vidas por la experiencia de un mundo sistémicamente en desplazamiento.

3 Si entendemos que el desplazamiento lo es siempre de un lugar a otro, todo acto de desplazamiento queda por ello configurado originariamente como un acto de salida $y_{\text {, simultá- }}$ neamente, como acto de llegada a otro lugar.

4 AA.W.: La situación de los refugiados en el mundo, ACNUR, Barcelona, Icaria, 2006. Junto a los datos del Anuario Estadístico 2008 y la Unidad de Registro y Estadística del Alto Comisionado de las Naciones Unidas para los Refugiados, publicados en AA.W.: "Atlas geopolítico 2010 Le Monde Diplomatique", Valencia, Ediciones Cybermonde, 2010

5 En la terminología técnica, desplazado es un término que sirve para referirse a la persona o personas que se ve motivada a trasladar su residencia dentro de su propio pais por motivos varios que pueden ir, tos bélicos. Lo utilizo en cambio sobrepasando estas limitaciones para referirme al fenómeno general de la migración por dos motivos: a) porque la lógica local que inspira su restricción me parece disuelta en la actualidad, es decir, no creo que sea útil considerar que los desplazamientos de población dentro de un país carecen de consecuencias en la globalidad sino más bien al contrario; b) porque tal concepto así implementado me permite referirme de un modo más adecuado a refugiados, emigrados y exiliados, de una sola vez y vinculados en lo que de común hay en sus experiencias.

6 Nótese que dicho sintagma refleja el estatuto de las personas desplazadas, es decir, no son juzgados sino administrados como enseres por las autoridades competentes en la "gestión" de "flujos humanos".

7 Por mundo entiendo aquí un orden coherente de sentido que dé unidad a las distintas experiencias vitales. Espacios donde diversos relatos sobre la realidad configuren visiones distintas de ella. La globalización ha derribado a los diversos mundos para diseñar tan sólo uno, de alcance global, y cada vez en mayor desintegración.

8 Esta situación recuerda la experiencia de los amotinados en el filme Rebelión a bordo (Lewis Milestone, 1962). En él se relata cómo una vez producido un motín y logrado el triunfo por parte de los rebeldes, éstos se deciden a huir de la justicia y a defender su causa por miedo al presidio en la creencia ilusoria según la cual en su vida en el mar gozarán de la libertad del afuera. A la postre sin embargo, reciben el golpe de su
Aceptado: 21 de diciembre de 2011 
nueva condena a la huida sin fin, tal como se refleja en la cita arriba reproducida.

9 "La igualdad de condición, aunque es ciertamente un requerimiento básico de la justicia, figura, sin embargo, entre los mayores y más inciertos riesgos de la humanidad moderna. (...) Esta perversión de la igualdad, de un concepto político a un concepto social, es aún mucho más peligrosa cuando una sociedad no deja el más pequeño espacio para los grupos e individuos especiales, porque sus diferencias se tornan aún más conspicuas. El gran reto planteado al período moderno y su peculiar peligro ha consistido en el hecho de que por vez primera el hombre se enfrentara con el hombre sin la protección de circunstancias y condiciones diferentes" (Arendt 2004, 105-106).

10 El par que forman los conceptos de refugio-derechos del hombre nos lleva a reflexionar sobre el núcleo mismo de la filosofía política y del derecho que desarrolla la modernidad: ciudadanía, soberanía y legitimidad. Se trata de una reflexión sobre el poder y la inclusión/exclusión en la comunidad política que no deja de ser otra cara del problema de la relación entre las partes y el todo. Cuando el todo queda puesto en entredicho por una parte incapaz de ser integrada en él se torna inverosimil, bien por ser esta parte radicalmente otra e imposible su inclusión (en el orden del derecho), bien porque la voluntad de su exclusión hace al todo impotente (pues no es sino una parte mayor que la excluida).

11 Es decir, la privación de la condición de ciudadano o la privación de la nacionalidad, hechos considerados como una lesión grave de los derechos humanos.

12 Birgmingham $(2006,2)$ sostiene esta misma posición, y cita en su defensa las interpretaciones que hacen al respecto de este asunto autores como Rawls o lgnatieff.

\section{BIBLIOGRAFÍA}

Arendt, H. (2004): Los orígenes del totalitarismo, Madrid, Taurus.

Benhabib, S. (2005): Los derechos de los otros, Barcelona, Gedisa.

Birmingham, P. (2006): Hannah Arendtand Human Rights, Bloomington, Indiana U.P.

Ferrajoli, L. (1999): Derechos y garantías: Ia ley del más débil, Madrid, Trotta.

Maalouf, A. (2007): Identidades asesinas, Madrid, Alianza.

Marshall, Thomas H. (1998): Ciudadanía y clase social, Alianza, Madrid.

Mezzadra, S. (2005): Derecho de fuga, Madrid, Traficantes de sueños.

Naïr, S. (2006): "Movimientos migratorios", en Claridad, n. 6 , 30-39.

Sayad, A. (2010): La doble ausencia, BarceIona, Anthropos

Soysal, Y. N. (1994): Limits of Citizenship, Chicago-Londres, University of Chicago Press.

Vitale, E. (2006): Ius migrandi, Madrid, Melusina.

Weber, M. (1987): Ensayos sobre sociología de la religión, 3 vols., Madrid, Taurus. 